\title{
Prevalence, Detection, Management, and Control of Hypertension in Ashanti, West Africa
}

\author{
Francesco P. Cappuccio, Frank B. Micah, Lynsey Emmett, Sally M. Kerry, Samson Antwi, \\ Ruby Martin-Peprah, Richard O. Phillips, Jacob Plange-Rhule, John B. Eastwood
}

\begin{abstract}
Hypertension and stroke are important threats to the health of adults in sub-Saharan Africa. Nevertheless, detection of hypertension is haphazard and stroke prevention targets are currently unattainable. Prevalence, detection, management, and control of hypertension were assessed in 1013 men $(n=385)$ and women $(n=628)$, both aged 55 [SD 11] years, living in 12 villages in Ashanti, Ghana. Five hundred thirty two lived in semi-urban and 481 in rural villages. The participants underwent measurements of height, weight, and blood pressure (BP) and answered a detailed questionnaire. Hypertension was defined as $\mathrm{BP} \geq 140$ and/or $\geq 90 \mathrm{~mm} \mathrm{Hg}$ or being on drug therapy. Women were heavier than men. Participants in semi-urban areas were heavier and had higher BP (129/76 [26/14] versus 121/72 [25/13] mm Hg; $P<0.001$ for both) than in rural areas. Prevalence of hypertension was $28.7 \%$ overall and comparable in men and women, but higher in semi-urban villages (32.9\% [95\% CI 28.9 to 37.1] versus $24.1 \%$ [20.4 to 28.2]), and increased with age. Detection rate was lower in men than women (13.9\% versus $27.3 \% ; P=0.007)$. Treatment and control rates were low in both groups $(7.8 \%$ and $4.4 \%$ versus $13.6 \%$ and $1.7 \%)$. Detection, treatment, and control rates were higher in semi-urban $(25.7 \%, 14.3 \%$, and $3.4 \%)$ than in rural villages $(16.4 \%, 6.9 \%$, and $1.7 \%)$. Hypertension is common in adults in central Ghana, particularly in urban areas. Detection rates are suboptimal in both men and women, especially in rural areas. Adequate treatment of high BP is at a very low level. There is an urgent need for preventive strategies on hypertension control in Ghana. (Hypertension. 2004;43:1017-1022.)
\end{abstract}

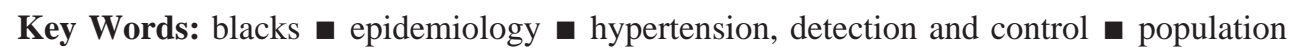

W orldwide, hypertension is common ${ }^{1}$ and now regarded as a major public health problem..$^{2}$ In a recent study, the prevalence of hypertension was found to be $28 \%$ in North America and $44 \%$ in western Europe. ${ }^{1}$ Until recently, hypertension was thought to be rare in rural $\mathrm{Africa}^{3-4}$; on the other hand, hypertension and its complications, including stroke, heart failure, and renal failure, have been reported in blacks all over the world. Hypertension is now being widely reported in Africa and is the most common cause of cardiovascular disease on the continent. ${ }^{5}$ It is also a major factor in the high mortality of adults in sub-Saharan Africa. ${ }^{6}$ In Ghana, hypertensive renal disease is a common complication in both Kumasi and Accra. ${ }^{7-8}$

In Ghana, earlier studies revealed a hypertension prevalence of $4.5 \%$ among rural dwellers and of $8 \%$ to $13 \%$ in the town. ${ }^{9}$ This was part of an evaluation of the health burden of cardiovascular diseases in Accra and was to form the basis for setting up a hypertension control program. More recently, the prevalence of hypertension in urban Accra was found to be $28.3 \%$ (crude) and $27.3 \%$ (age-standardized). ${ }^{10}$ Hypertension is becoming more common as urbanization increases, and this has been shown in several studies in Africa. ${ }^{11}$

A number of studies of urban African populations have shown a positive correlation between blood pressure, age, and gender. The prevalence of hypertension in Accra was much higher in men than in women aged $<40$ years but similar above that age. ${ }^{9}$ On the other hand, in a recent study prevalence was higher in women than in men. ${ }^{10}$

In the developed world, the detection, treatment, and control of hypertension have been characterized by the "rule of halves,"12 although recent evidence suggests that there has been a general improvement. ${ }^{13}$ However, in much of sub-Saharan Africa, due to scarce resources and inadequate healthcare provision, detection, treatment, and control are very poor. . $^{9,10,14}$

The aim of our study was to assess the prevalence, detection, management, and control of hypertension among men and women living in rural and semi-urban villages in the Ashanti Region of Ghana, West Africa. ${ }^{15}$ It was part of a community-based study of the prevention of hypertension and stroke in the same region.

Received November 17, 2003; first decision December 15, 2003; revision accepted February 27, 2004.

From the Department of Community Health Sciences (F.P.C., F.B.M., L.E., S.M.K., J.P-R.) and Renal Medicine (L.E., J.P-R, J.B.E.), St George's Hospital Medical School, London, United Kingdom; and Department of Medicine (F.B.M., S.A., R.M-P., R.O.P., J.P-R.) Komfo Anokye Teaching Hospital, Kumasi, Ghana.

The study was supported by the Wellcome Trust (060415/Z/00/Z). F.B.M. is supported by a Wellcome Trust Master's Research Training Fellowship (069500/Z/02/Z).

Correspondence to Francesco P. Cappuccio, MD FRCP, Department of Community Health Sciences, St. George's Hospital Medical School, Cranmer Terrace, London SW17 0RE, UK. E-mail f.cappuccio@sghms.ac.uk

(C) 2004 American Heart Association, Inc. 
TABLE 1. Characteristics of the Population by Locality and Gender

\begin{tabular}{lccccc}
\hline Variables & $\begin{array}{c}\text { All } \\
(\mathrm{n}=1013)\end{array}$ & $\begin{array}{c}\text { Rural } \\
(\mathrm{n}=481)\end{array}$ & $\begin{array}{c}\text { Semi-urban } \\
(\mathrm{n}=532)\end{array}$ & $\begin{array}{c}\text { Men } \\
(\mathrm{n}=385)\end{array}$ & $\begin{array}{c}\text { Women } \\
(\mathrm{n}=628)\end{array}$ \\
\hline Age $(\mathrm{y})$ & $54.7(11.3)$ & $54.5(11.2)$ & $54.9(11.4)$ & $54.6(10.9)$ & $54.8(11.5)$ \\
Height $(\mathrm{cm})$ & $160.4(8.5)$ & $160.6(8.6)$ & $160.3(8.5)$ & $166.6(7.0)$ & $156.6(7.0) \S$ \\
Weight $(\mathrm{kg})$ & $54.3(11.2)$ & $51.1(9.5)$ & $57.2(11.9) \dagger$ & $56.3(9.8)$ & $53.0(11.9) \S$ \\
BMI $\left(\mathrm{kg} / \mathrm{m}^{2}\right)$ & $21.1(4.2)$ & $19.8(3.2)$ & $22.3(4.6) \dagger$ & $20.2(3.1)$ & $21.1(4.6) \S$ \\
Systolic BP $(\mathrm{mm} \mathrm{Hg})$ & $125.5(26.1)$ & $121.5(25.1)$ & $129.2(26.4) \dagger$ & $126.3(24.4)$ & $125.1(27.0)$ \\
Diastolic BP $(\mathrm{mm} \mathrm{Hg})$ & $74.4(13.6)$ & $72.3(13.2)$ & $76.2(13.8) \dagger$ & $75.8(13.7)$ & $73.5(13.5) \S$ \\
Pulse Rate $(\mathrm{bpm})$ & $74.2(12.0)$ & $74.4(12.2)$ & $74.0(11.9)$ & $71.3(11.4)$ & $75.9(12.1) \S$ \\
Hypertension $\mathrm{n}(\%)$ & $291(28.7)$ & $116(24.1)$ & $175(32.9) \ddagger$ & $115(29.9)$ & $176(28.0)$ \\
\hline
\end{tabular}

Results are mean (SD).

*Blood pressure $\geq 140$ and/or $\geq 90 \mathrm{~mm} \mathrm{Hg}$, or being on antihypertensive medication.

$\dagger P<0.001$ vs rural; $\ddagger P=0.002 ; \S P<0.001$ vs men.

\section{Methods}

All procedures were carried out according to a study protocol approved by the Local Ethics Committee in London as well as the Committee on Human Research Publication and Ethics, School of Medical Sciences, Kwame Nkrumah University of Science and Technology, Kumasi, Ghana. Twelve villages (6 semi-urban and 6 rural) that had little day-to-day contact with each other in the Ejisu-Juabeng and Kumasi Districts of the Ashanti Region of Ghana were selected in consultation with the local health workers. ${ }^{15}$ Following agreement with the chiefs and elders in each of the villages, a team of fieldworkers carried out a population census between January and March $2001^{15}$ to create an age-and-sex register for the villages. Full details are reported elsewhere. ${ }^{15}$ In brief, a total of 16965 individuals (6597 rural and 10368 semi-urban) from 1460 households (750 rural and 710 semi-urban) were seen. The 12 villages had an average population (all ages) of 1414 per village (range 562 to 1966). ${ }^{15}$ The adult population ( $\geq 16$ years of age) was $38 \%$ in rural and $33 \%$ in semi-urban villages. The population structure of these villages was comparable to that reported for Ghana as a whole. There were 2743 adults aged 40 to 75 years.

Between June 2001 and June 2002, the study team consisting of doctors, nurses (clinical and community health nurses), and clerks assisted by the various village health committees, set up a data collection center in each village school (or some other convenient place). All members of the team had been trained to take measurements and to carry out procedures according to a standardized protocol developed in the coordinating center in London. A stratified random sample of 1896 inhabitants aged 40 to 75 years was invited to take part. Stratification was by age and sex within village, so that the total sample selected matched the overall population structure and there were no differences between the villages in the age and sex distribution. The proportion of the invited village population varied according to village size, with a higher proportion in smaller villages. At a meeting between the research team and the selected individuals, the study and the participant's role were explained. The information sheet and consent form (available in both English and Twi, the local language) were read and explained to each participant who, if agreeing to take part, gave consent either by signing his or her name or applying a left thumbprint. A total of 1013 adults (53.4\% of those invited) agreed to take part. The response rate varied considerably between villages (range $40 \%$ to $88 \%$ ). Responders were 2.0 (95\% CI 0.8 to 3.1 ) years older than nonresponders, and men were less likely to respond than women in semi-urban villages ( $41 \%$ versus $56 \%$ ), but not in rural villages. No more information could be taken from nonresponders. A detailed questionnaire including tribe, religion, language, work, education, housing, personal and family medical history, smoking, and diet was administered by a clerk. Because many individuals did not have birth certificates or other form of identification giving date of birth, ${ }^{15}$ the fieldworkers used a guide sheet of important dates and events in Ghana's recent history to ensure that the age recorded was as accurate as possible.
Height was measured without shoes, using a wooden platform and a height rule, to the nearest $0.5 \mathrm{~cm}$. Weight was measured to the nearest $0.5 \mathrm{~kg}$ with manual Seca 761 scales (Vogel \& Halke, Germany) after the participants had removed their outer garments and footwear. Body mass index (BMI) was calculated as weight $(\mathrm{kg})$ divided by height $\left(\mathrm{m}^{2}\right)$. Blood pressure (BP) and pulse rate were measured after the participant had been sitting upright for at least 5 minutes with an automatic machine (OMRON HEM705CP sphygmomanometer; Omron Matsusaka Co Ltd, Japan). The appropriate cuff size $(13 \times 23 \mathrm{~cm}$ or $16 \times 30 \mathrm{~cm})$ was used. Three readings were taken 1 minute apart. The first was discarded, and the mean of the last 2 readings were used in the analysis. Participants were also asked whether they were on regular antihypertensive drug therapy. Hypertension was defined as a systolic BP $\geq 140 \mathrm{~mm} \mathrm{Hg}$ and/or a diastolic $\mathrm{BP} \geq 90 \mathrm{~mm} \mathrm{Hg}$ or being on drug therapy for hypertension.

Locality and gender differences in blood pressure were compared using a 2-sample $t$ test. Exact confidence intervals for prevalence rates were computed using a binomial distribution, and gender and locality differences compared using a $\chi^{2}$ test.

\section{Results}

\section{Characteristics of the Study Population}

There were 1013 participants in the study (385 men and 628 women)(5th-95th percentile of aged 40 to 75 years); of these 532 were from semi-urban and 481 from rural villages. Men and women were of comparable age (55 [SD 11] versus 55 [SD 11] years) as were semi-urban and rural participants. Women were heavier but shorter than men and, therefore, had a higher BMI (21.6 [4.6] versus 20.2 [3.1] kg/m²; $P<0.001)$. Semi-urban participants were of comparable height to rural dwellers but were heavier and had a significantly higher BMI (Table 1). Systolic BP increased with age (Figure 1, left), while diastolic BP peaked in the 55 to 64 year group then reached a plateau (Figure 1, right). This pattern was seen in both rural and semi-urban participants (Table 2). Diastolic, but not systolic BP, was higher in men than in women (126/76 [24/14] versus 125/74 [27/14] mm Hg; $\mathrm{P}=0.45$ / 0.01). Both systolic and diastolic BPs were higher in the semi-urban participants (Table 1). These differences were confirmed after adjustment for the confounding effects of age, gender, and BMI (systolic BP difference: $5.1 \mathrm{~mm} \mathrm{Hg}$ [1.9 to 8.3]; diastolic BP difference: $2.1 \mathrm{~mm} \mathrm{Hg}$ [0.4 to 3.8]).

\section{Prevalence of Hypertension}

There were 291 hypertensives (115 men and 176 women, 116 rural and 175 semi-urban) giving an overall prevalence of 

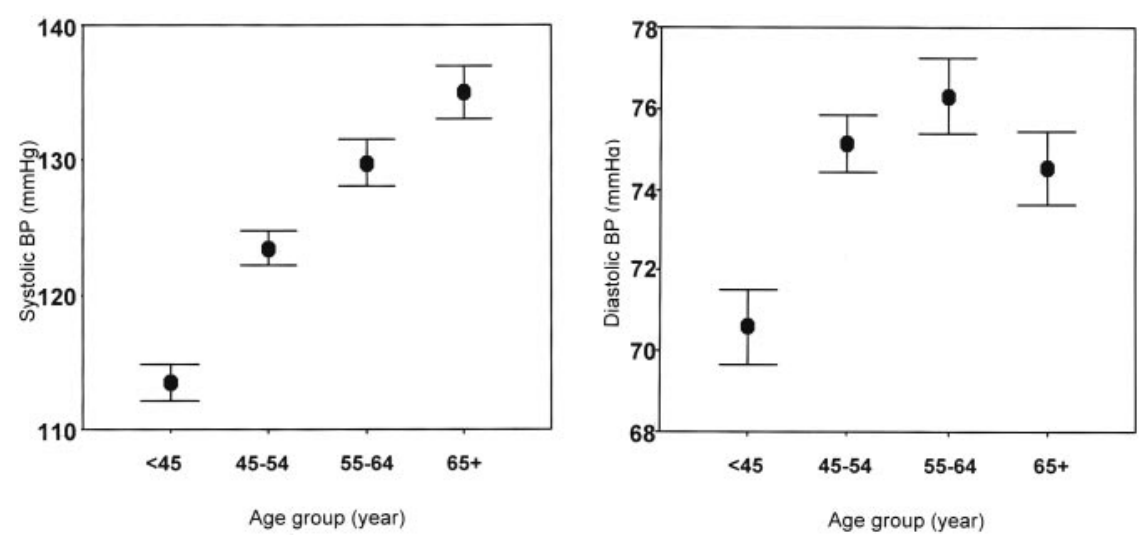

Figure 1. Systolic and diastolic blood pressure by age group in Ashanti, West Africa. Results are shown as mean and standard error. hypertension of $28.7 \%$ (95\% C.I. 26.0 to 31.6). Hypertension prevalence was comparable in men and women (29.9\% [25.3 to 34.7 ] versus $28.0 \%$ [24.5 to 31.7 ]). Hypertension was more prevalent in semi-urban than rural villagers (32.9\% [28.9 to 36.9 ] versus $24.1 \%$ [20.4 to 28.2]; $P=0.002$ ). The prevalence rate increased with age in both men and women (Figure 2, top), and in both rural and semi-urban participants (Figure 2, bottom).

\section{Detection, Management, and Control of Hypertension}

Overall $22.0 \%(64 / 291)$ were aware of being hypertensive, $11.3 \%$ (33/291) were on antihypertensive treatment but only $2.8 \%$ of the total $(8 / 291)$ had their blood pressure adequately controlled (ie, $<140 / 90 \mathrm{~mm} \mathrm{Hg}$ ). The detection rate was lower in men than in women (odds ratio $[\mathrm{OR}]=0.43[0.23$ to 0.80]) (Figure 3, top). Both men and women had very low treatment and control rates (Figure 3, top). Semi-urban participants had higher detection, treatment, and control rates than rural participants (Figure 3, bottom).

\section{Discussion}

There have been a number of surveys of blood pressure distribution, and of the prevalence, detection, management, and control of hypertension in West Africa.4,7-10,16-31 Data have been published from Nigeria, Ghana, Cameroon, the Gambia, Sierra Leone, Liberia, and Senegal. All these studies have shown a high (and rising) prevalence of hypertension generally, and a consistently higher prevalence in urban than in rural areas (Table 3). They have also shown low rates of detection and correspondingly low rates of treatment and control. Clearly, therefore, there is a pressing need for robust strategies to deal with this serious threat to the health of the people of sub-Saharan Africa. ${ }^{9-10,16-31}$

In Ghana, studies were carried out in Greater Accra from 1972 to 1987 as part of an investigation into the health burden of cardiovascular diseases. The prevalence of hypertension (BP $\geq 160 / 95 \mathrm{~mm} \mathrm{Hg}$ ) was found to be $4.5 \%$ in the rural areas and $8 \%$ to $13 \%$ in the city itself. Among the urban dwellers, $24 \%$ knew they were hypertensive and $7.2 \%$ were on some form of treatment, though only half were being treated adequately.4,9,28 More recently, in Accra, Amoah found overall crude and age-standardized prevalence rates of hypertension ( $\mathrm{BP} \geq 140 / 90 \mathrm{~mm} \mathrm{Hg}$ ) to be $28.3 \%$ and $27.3 \%$, respectively. ${ }^{10}$ Hypertension was more common in women than men. Overall, only $34 \%$ were aware that their blood pressure was high and $22.2 \%$ were taking antihypertensive medication, but only $6.2 \%$ had optimal blood pressure control. ${ }^{10}$

Our present study is unique in several ways. First, it is the first report in Ghana of blood pressure in a population outside

TABLE 2. Blood Pressure by Age Group, Locality, and Gender

\begin{tabular}{|c|c|c|c|c|c|c|}
\hline Age Group (y) & $\mathrm{n}$ & $\begin{array}{c}\text { Systolic BP } \\
(\mathrm{mm} \mathrm{Hg})\end{array}$ & $\begin{array}{c}\text { Diastolic BP } \\
\text { (mm Hg) }\end{array}$ & $\mathrm{n}$ & $\begin{array}{l}\text { Systolic BP } \\
(\mathrm{mm} \mathrm{Hg})\end{array}$ & $\begin{array}{c}\text { Diastolic BP } \\
(\mathrm{mm} \mathrm{Hg})\end{array}$ \\
\hline & \multicolumn{4}{|c|}{ Rural $(n=481)$} & \multicolumn{2}{|c|}{ Semi-urban $(n=532)$} \\
\hline$<45$ & 91 & $109.2(16.0)$ & $67.8(11.3)$ & 106 & $117.1(19.7)$ & $73.0(13.6)$ \\
\hline $45-54$ & 170 & $122.4(24.7)$ & $74.1(13.1)$ & 190 & $124.4(23.9)$ & $76.0(13.7)$ \\
\hline $55-64$ & 121 & $123.4(25.0)$ & $73.3(12.8)$ & 107 & $137.1(27.4)$ & $79.7(14.4)$ \\
\hline 65 and over & 99 & $129.0(29.0)$ & $72.2(14.4)$ & 129 & $139.7(28.1)$ & $76.3(13.0)$ \\
\hline \multirow[t]{2}{*}{$P$ for linear regression } & & $<0.001$ & 0.103 & & $<0.001$ & 0.022 \\
\hline & \multicolumn{4}{|c|}{ Men $(n=385)$} & \multicolumn{2}{|c|}{ Women $(n=628)$} \\
\hline$<45$ & 77 & $120.9(18.6)$ & $75.1(13.9)$ & 120 & $108.7(16.8)$ & $67.7(11.3)$ \\
\hline $45-54$ & 130 & $124.6(22.2)$ & $76.6(13.6)$ & 230 & $122.8(25.4)$ & $74.3(13.3)$ \\
\hline $55-64$ & 94 & $130.0(25.5)$ & $77.3(14.4)$ & 134 & $129.7(28.1)$ & $75.6(13.6)$ \\
\hline 65 and over & 84 & $130.0(30.0)$ & $73.4(12.9)$ & 144 & $138.1(28.0)$ & $75.2(14.2)$ \\
\hline$P$ for linear regression & & $<0.001$ & 0.856 & & $<0.001$ & $<0.001$ \\
\hline
\end{tabular}

Results are mean (SD). 

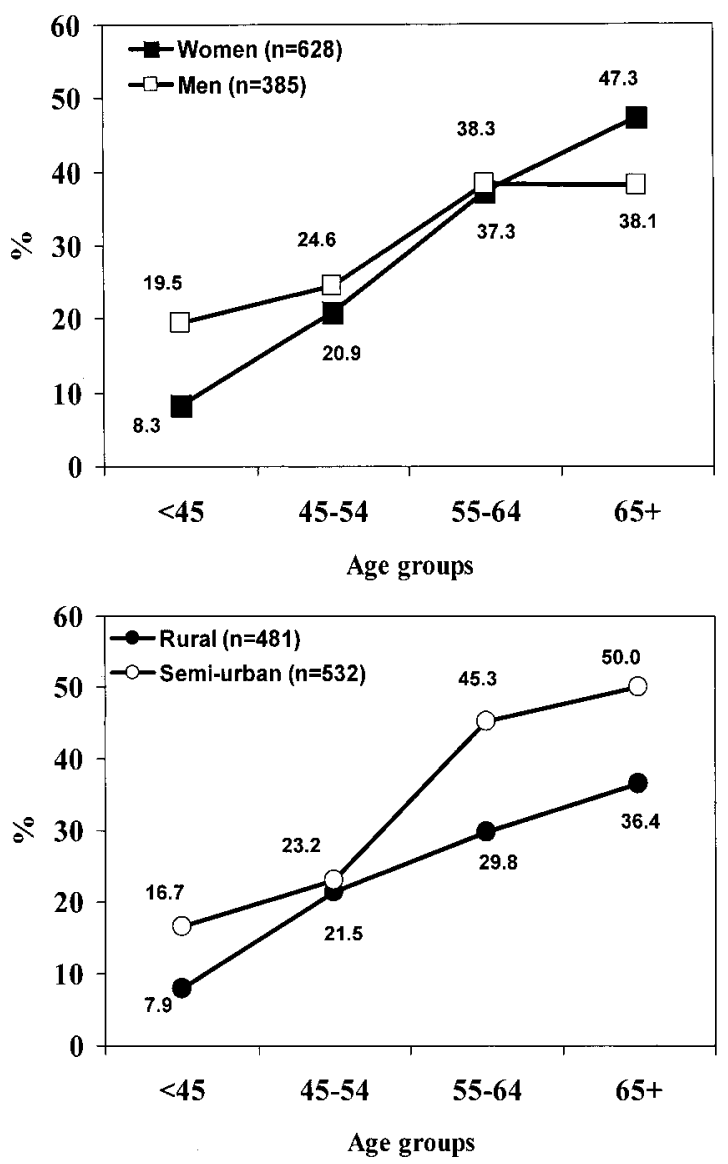

Figure 2. Top, Prevalence of hypertension by gender and age group in Ashanti, West Africa. Hypertension is defined as systolic BP $\geq 140$ and /or diastolic BP $\geq 90 \mathrm{~mm} \mathrm{Hg}$, or on antihypertensive medication. Bottom, Prevalence of hypertension, as defined above, in rural and semi-urban villages by age group.

the Greater Accra area. The present survey was carried out in the area around Kumasi, the second largest city in Ghana, where hitherto data on the prevalence of hypertension has been lacking. A report from the Teaching hospital, however, suggested that hypertension was a common cause of morbidity and mortality. ${ }^{7}$ Second, stratified random samples of the 12 villages were studied. The part of Ghana this encompassed was a large area of approximately $960 \mathrm{~km}^{2}$, so it is possible that our findings could be taken as representative of other villages in Ashanti and in Ghana as a whole. ${ }^{15}$ Third, the present study compares rural with semi-urban villages (instead of large urban communities). In the present study "rural" refers to villages lacking any real infrastructure; they had no main water supply or sewage and often lacked electricity. These villages were up to $40 \mathrm{~km}$ from Kumasi. In contrast, most of the "semi-urban" villages had main water and all had electricity; they were within $15 \mathrm{~km}$ of Kumasi. ${ }^{32}$ This last characteristic is important because none of the villages we studied could be regarded as fully urbanized, unlike the study of the Greater Accra region mentioned above. However, there were significant differences in blood pressure, body weight, and prevalence of hypertension between the two settings, indicating that a limited move toward urbanization can lead to important alterations in cardiovascular risk factors.
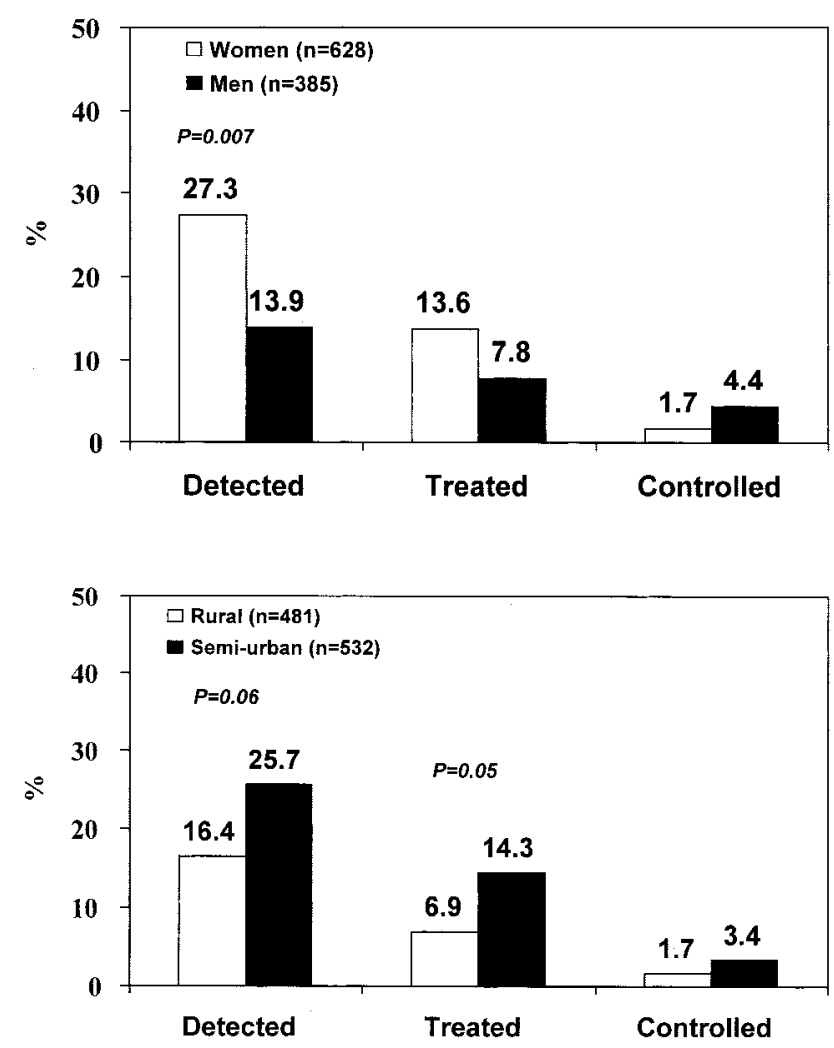

Figure 3. Top, Proportion of people with hypertension, who were detected, treated, and controlled (ie, BP $<140$ and $90 \mathrm{~mm} \mathrm{Hg}$ ) by gender and age group in Ashanti, West Africa. Hypertension is defined as systolic BP $\geq 140$ and /or diastolic $\mathrm{BP} \geq 90 \mathrm{~mm} \mathrm{Hg}$, or on anti-hypertensive medication. Bottom, Proportion of people with hypertension, as defined above, who were detected, treated, and controlled (ie, BP $<140$ and $90 \mathrm{~mm} \mathrm{Hg}$ ) in rural and semi-urban villages by age group.

\section{Prevalence of Hypertension}

The overall prevalence of hypertension in our study was high at $28.7 \%$ and remarkably similar to the prevalence of $28.3 \%$ found in Accra. ${ }^{10}$ These values are much higher than the $14.5 \%$ found in Nigeria and $16.9 \%$ in Cameroon, but lower than the value of $32.6 \%$ for blacks in the United States. ${ }^{24}$ Hypertension was more common in the semi-urban areas compared with the rural areas. This is similar to other reports from West Africa, with the exception of Nigeria where rural and urban prevalences have been found to be similar. ${ }^{24}$ As mentioned earlier, comparisons between studies are fraught with difficulty as the definitions and characteristics of rural and urban settings can differ substantially between studies. ${ }^{32}$ Furthermore, the participants in our study were relatively lean, unlike many studies of African populations. ${ }^{10,24,31} \mathrm{We}$ found that the prevalence of hypertension was higher in men than women, whereas in Accra the reverse was found. ${ }^{10}$ In general, no clear pattern of association between hypertension and gender has emerged. In the International Study of Hypertension in Blacks, for example, there was a higher prevalence of hypertension in men than women in Nigeria and urban Cameroon, but in rural Cameroon the prevalence was higher in women. ${ }^{24}$ In our study, prevalence rates showed a consistent increase with age in men and women in both rural and semi-urban villages. 
TABLE 3. Prevalence of Hypertension in Selected Population Studies in Sub-Saharan Africa

\begin{tabular}{|c|c|c|c|c|c|}
\hline \multirow{2}{*}{$\begin{array}{l}\text { First Author } \\
\text { (Year of Publication) }\end{array}$} & \multirow[b]{2}{*}{ Country } & \multirow{2}{*}{$\begin{array}{l}\text { Population } \\
\text { Type }\end{array}$} & \multirow{2}{*}{$\begin{array}{l}\text { Age } \\
\text { Group }\end{array}$} & \multicolumn{2}{|c|}{$\begin{array}{c}\text { Prevalence of } \\
\text { Hypertension* (\%) }\end{array}$} \\
\hline & & & & Men & Women \\
\hline \multirow[t]{7}{*}{ Akinkugbe $^{18}$ (1968) } & Nigeria & Rural & $40-44$ & 15.2 & 13.1 \\
\hline & & & $45-49$ & 14.4 & 39.4 \\
\hline & & & $50-54$ & 23.3 & 33.6 \\
\hline & & & $55-59$ & 20.5 & 29.0 \\
\hline & & & $60-64$ & 44.6 & 41.6 \\
\hline & & & 65-69 & 27.6 & 39.5 \\
\hline & & & $70+$ & 45.0 & 39.3 \\
\hline \multirow[t]{4}{*}{ Giles $^{29}$ (1994) } & Liberia & Rural & $40-44$ & 18 & 25 \\
\hline & & & $45-49$ & 16 & 36 \\
\hline & & & $50-54$ & 18 & 34 \\
\hline & & & $55+$ & 20 & 50 \\
\hline \multirow[t]{3}{*}{ Cooper $^{24}$ (1997) } & Nigeria & Rural+Urban & $25+$ & $14.7 \dagger$ & $14.3 \dagger$ \\
\hline & Cameroon & Rural & $25+$ & $14.2 \dagger$ & $16.3 \dagger$ \\
\hline & & Urban & $25+$ & $22.8 \dagger$ & $16.0 \dagger$ \\
\hline \multirow[t]{2}{*}{ Mbanya $^{23}$ (1998) } & Cameroon & Rural & $25-74$ & 12.7 & 8.8 \\
\hline & & Urban & & 23.8 & 18.7 \\
\hline \multirow[t]{4}{*}{ Edwards $^{30}(2000)$} & Tanzania & Rural & $35-54$ & 40.6 & 38.8 \\
\hline & & & $55+$ & 54.0 & 61.0 \\
\hline & & Urban & $35-54$ & 46.6 & 52.3 \\
\hline & & & $55+$ & 77.8 & 69.0 \\
\hline Steyn ${ }^{31}$ (2001) & S. Africa & National & $15+$ & $25.1 \dagger$ & $25.3 \dagger$ \\
\hline Amoah $^{10}(2003)$ & Ghana & Urban & $25+$ & $27.6 \dagger$ & $29.5 \dagger$ \\
\hline
\end{tabular}

*Hypertension defined as SBP $\geq 140$ and/or DBP $\geq 90 \mathrm{~mm} \mathrm{Hg}$ or being on drug therapy.

†Age-adjusted.

\section{Detection, Management, and Control of High Blood Pressure}

A number of past studies of hypertension in the developed world have reported low rates of detection, treatment, and control. More recently, however, rates have much improved and are well above the "rule of halves." 12 Studies from Africa and other developing countries have shown very low rates. In our study, the overall detection rate was $22 \%$, and rates of treatment and control were $11.3 \%$ and $2.8 \%$, respectively. These figure are very low compared with rates reported from Accra and elsewhere. $^{9-10,23}$ Detection rate was lower in men than in women, and lower in rural than in semi-urban participants. The reasons for the gender inequalities in the detection of hypertension are not known, but we believe that hypertension in the women, many of whom had children, was first detected during pregnancy or during the postpartum period. In other words, before they entered the age group examined in our study, the women had more opportunity to use health services than the men. Not only had they received care in connection with pregnancy, but they had also had a further opportunity when taking their babies and children to see health workers.

\section{Potential Limitations of Our Study}

In a study such as we have described, biases can potentially arise in 3 main ways: from the method used to select the villages, from the methods used to select participants, and from different response rates. The villages were selected so that there were 6 rural villages and another 6 close to Kumasi, yet taking care not to induce too great a population difference. Care was also taken to make sure that the villages chosen had little day-to-day contact with each other and used different markets. This was important because the study involved a community-based trial of health promotion. ${ }^{15}$ Selection of participants in each village was by stratified random sampling following a population census. Stratification was by age and gender so that the total sample selected would represent the overall population structure and to ensure that the age and gender of the participants in the villages would be similar. The response rate to the invitation for screening was estimated at $53 \%$. This is a low response rate, and it was due to a number of factors. The survey was carried out in 2 main sessions each involving 6 villages. The second set of villages were surveyed more than 1 year after the census, and, by the time of the second visit, a number of individuals had migrated from the villages; some of the older inhabitants had died. Further, the main study (not reported here) involved blood sampling. This was viewed with a high degree of suspicion by some of the inhabitants, particularly at a time when HIV/ AIDS awareness was a government priority. Some people may have been unable to attend the data collection center due to work commitments, particularly those working in the city. Finally, this study was part of an intervention study that was to span 6 months. Although the participants were unaware of the specific objectives of the study at the time of the baseline assessment, selected participants who showed no commitment to finishing the project were not enrolled. Notwithstand- 
ing these shortcomings, and in view of the external consistency of our data with those of similar studies, ${ }^{10}$ our results may well be representative of the Ashanti Region of Ghana as a whole and be reasonably used to formulate local health policy, at least for the age groups studied.

\section{Perspectives}

Hypertension is common in West Africa and must be regarded as a major public health issue. Our study has shown a high prevalence hypertension, even in rural areas, but worrisome low rates of detection, treatment, and control. Clearly, the government of Ghana will have high blood pressure on its health agenda. It will need to formulate a national control program as well as national guidelines for the detection and management of hypertension. Other measures such as a reduction in salt intake, ${ }^{33-35}$ which is currently recommended by the World Health Organization, ${ }^{6}$ should also be promoted, while low-cost drug treatment is being implemented. ${ }^{11}$

\section{Acknowledgments}

We thank the many enthusiastic workers in Ghana who have contributed to the study. They are: nurses Agnes Asare Bediako, Hannah Boatemaa, Sarah Manu, Olivia Otoo Mensah, Vivian Osei, Joyce Prempeh, Joyce Yalleh, Sarah Gbedzo, and Angelina Abban; community health workers Comfort Frimpong and Elizabeth Quaicoo; and fieldworkers Kwasi Adjei, Charles Ankisiba, Stephen Boate, and Daniel Dwamena. We also thank Akwasi Gyebi who drew the maps and Martin Adi-Darko for helping develop the educational material. We are also grateful to Anthony Richard Edmundson from the Land Administration Research Centre, Kwame Nkrumah University of Science and Technology, Kumasi; Douglas Acheampong from the Ejisu-Juabeng District Health Directorate, Ministry of Health, Ghana; and all those who helped at the different stages of the project. We would also like to thank the chiefs and elders of the 12 villages for their help. F.P.C. is a member of the St George's Cardiovascular Research Group.

\section{References}

1. Wolf-Maier K, Cooper RS, Banegas JR, Giampaoli S, Hense H, Joffres M, Kastarinen M, Poulter N, Primatesta P, Rodriguez-Artalejo F, Stegmayr B, Thamm M, Tuomilehto J, Vanuzzo D, Vescio F. Hypertension prevalence and blood pressure levels in 6 European countries, Canada, and the United States. JAMA. 2003;289:2363-2369.

2. Murray CJ, Lopez AD. Mortality by cause for eight regions of the world. Global Burden of Disease. Lancet. 1997;349:1269-1276.

3. Shaper AG, Wright DH, Kyobe J. Blood pressure and body built in three nomadic tribes of northern Kenya. East Afr Med J. 1969;46:273-281.

4. Pobee JO, Larbi EB, Belcher DW, Wurapa FK, Dodu SR. Blood pressure distribution in a rural Ghanaian population. Trans R Soc Trop Med Hyg. 1977;71:66-72.

5. Cooper RS, Rotimi C. Establishing the epidemiologic basis for prevention of cardiovascular diseases in Africa. Ethn Dis. 1993;3:S13-S22.

6. World Health Organization. The World Health Report 2002. Reducing risks, promoting healthy life. Geneva, Switzerland: World Health Organization; 2002.

7. Plange-Rhule J, Phillips R, Acheampong JW, Saggar-Malik AK, Cappuccio FP, Eastwood JB. Hypertension and renal failure in Kumasi, Ghana. J Hum Hypertens. 1999;13:37-40.

8. Mate-Kole MO, Affram RK. Presentation and clinical course of End-Stage Renal Failure in Ghana. A preliminary prospective study. Ghana Med. J. 1990;24:164-168.

9. Pobee JOM. Community-based high blood pressure programs in subSaharan Africa. Ethn Dis. 1993;3:S38-S45.

10. Amoah AGB. Hypertension in Ghana: a cross-sectional community prevalence study in Greater Accra. Ethn Dis. 2003;13:310-315.

11. Cooper RS, Rotimi CN, Kaufman JS, Muna WF, Mensah GA. Hypertension treatment and control in sub-Saharan Africa: the epidemiological basis for policy. BMJ. 1998;316:614-617.
12. Smith WCS, Lee AJ, Crombie IK, Tunstall-Pedoe H. Control of blood pressure in Scotland: the rule of halves. BMJ. 1990;300:981-983.

13. Cappuccio FP, Cook DG, Atkinson RW, Strazzullo P. Prevalence, detection, and management of cardiovascular risk factors in different ethnic groups in south London. Heart. 1997;78:555-563.

14. Seedat YK, Seedat MA. An inter-racial study of the prevalence of hypertension in an urban South African population. Trans $R$ Soc Trop Med Hyg. 1982;76:62-71.

15. Plange-Rhule J, Cappuccio FP, Emmett L, Kerry SM, Edmundson AR, Acheampong D, Eastwood JB. A community study of health promotion in rural West Africa: details of a household survey and population census. $Q$ J Med. 2002;95:445-450.

16. Oviasu VO, Okupa FE. Relation between hypertension and occupational factors in rural and urban Africans. Bull World Health Organ. 1980;58: 485-489.

17. Akinkugbe OO. The Nigerian hypertension programme. J Hum Hypertens 1996;10:S43-S46.

18. Akinkugbe OO, Ojo AO. The systemic blood pressure in a rural Nigerian population. Trop Geogr Med. 1968;20:347-356.

19. Lisk DR, McEwen EK. The significance and trend of hypertension related deaths in urban Sierra Leonean Africans. J Hum Hypertens. 1996;10: 215-218.

20. van der Sande MAB, Bailey R, Faal H, Banya WA, Dolin P, Nyan OA, Ceesay SM, Walraven GE, Johnson GJ, McAdam KP. Nationwide prevalence study of hypertension and related non-communicable diseases. Trop Med Int Health. 1997;2:1039-1048.

21. van der Sande MAB, Milligan PJM, Walraven GEL, Dolmans WMV, Newport M, Nyan OA, Banya WAS, Thien TH, Ward R, McAdam KPWJ. Geographical variation in prevalence of hypertension within The Gambia. J Hum Hypertens. 2001;15:733-739.

22. Beiser M, Collomb H, Ravel J, Nafziger CJ. Systemic blood pressure studies among the Serer of Senegal. J Chron Dis. 1976;29:371-380.

23. Mbanya JC, Minkoulou EM, Salah JN, Balkau B. The prevalence of hypertension in rural and urban Cameroon. Int J Epidermiol. 1998;27: 181-185.

24. Cooper R, Rotimi C, Ataman S, McGee D, Osotmehin B, Kadiri S, Muna W, Kingue S, Fraser H, Forrester T, Bennett F, Wilks R. The prevalence of hypertension in seven populations of West African origin. Am J Public Health. 1997;87:160-168.

25. Pole D, Ikeme AC, Pobee JO, Larbi E, Williams H, Blankson J. The Mamprobi Survey-a screening survey for cardiovascular disease and risk factors in Africa: methodology and validity. Bull World Health Organ. 1979;57:81-87.

26. Ikeme AC, Pole DJ, Pobee JO, Larbi E, Blankson J, Williams H. Cardiovascular status and blood pressure in a population sample in Ghana-the Mamprobi survey. Trop Geogr Med. 1978;30:313-329.

27. Blankson JM, Larbi EB, Pobee JO. Blood pressure levels of African children. J Chron Dis. 1977;30:735-743.

28. Pobee JO, Larbi EB, Dodu SR, Pisa Z, Strasser T. Is systemic hypertension a problem in Ghana? Trop Doct. 1979;9:89-92.

29. Giles WH, Pacque M, Greene BM, Taylor HR, Munoz B, Cutler M, Douglas J. Prevalence of hypertension in rural West Africa. Am J Med Sci. 1994;308:271-275.

30. Edwards R, Unwin N, Mugusi F, Whiting D, Rashid S, Kissima J, Aspray TJ, Alberti KG. Hypertension prevalence and care in an urban and rural area of Tanzania. J Hypertens. 2000;18:145-152.

31. Steyn K, Gaziano TA, Bradshaw D, Laubscher R, Fourie J Hypertension in South African adults: results from the Demographic and Heath Survey, 1998. J Hypertens. 2001;19:1717-1725.

32. Kerry SM, Emmett L, Micah FB, Martin-Peprah R, Antwi S, Phillips RO, Plange-Rhule J, Eastwood JB, Cappuccio FP. Rural and semi-urban differences in salt intake, and its dietary sources, in Ashanti, West Africa. Ethn Dis. In press.

33. Cappuccio FP. Salt and blood pressure. Issues for population-based prevention and public health strategies. Public Health Medicine. 2000;2: $57-61$.

34. Cappuccio FP, Plange-Rhule J, Phillips RO, Eastwood JB. Prevention of hypertension and stroke in Africa. Lancet. 2000;356:677-678.

35. Adeyemo AA, Prewitt TE, Luke A, Omotade OO, Rotimi CN, Brieger WR, Cooper RS. The feasibility of implementing a dietary sodium reduction intervention among free-living normotensive individuals in south west Nigeria. Ethn Dis. 2002;12:207-212. 